\title{
SIZE EFFECTS IN THE COMPRESSIVE CRUSHING OF HONEYCOMBS
}

\author{
Erik C. Mellquistand Anthony M. Waas* \\ Composite Structures Laboratory, Aerospace Engineering Department, \\ University of Michigan, \\ Ann Arbor, Michigan 48109-2140.
}

\begin{abstract}
$\underline{\text { Abstract }}$
The effect of cell size on the out of plane compressive crushing response of circular cell polycarbonate honeycomb is presented. Over 100 experiments were conducted on specimens ranging in size from 1 to 169 cells (number of cells $=\mathrm{N}$ ). Experiments showed that for $\mathrm{N}<19$ there was a significant increase in crushing load. The maximum crushing load was observed where $\mathrm{N}=7$. Finite element (FE) analysis was used to better understand the behavior of the specimens during crushing and to validate experimental results. Currently a FE model has been developed for $\mathrm{N}=7$ cells, and in the future will be expanded for different values of $\mathrm{N}(\mathrm{N}=1-169)$ with a view to establishing the reasons for size effects.
\end{abstract}

\section{$\underline{\text { Introduction }}$}

Sandwich structures (that employ a honeycomb core between two relatively thin skins) are desirable in several engineering applications that require high strength to weight ratios. Because of their ability to absorb large amounts of energy, they are also often used as a "cushion" against external loads. Honeycomb sandwich structures are currently being used in many engineering applications, both within and outside of aerospace engineering. Most studies in the literature are related to one of the attributes (high strength/weight or increased energy absorption) mentioned above. In the latter case, when detailed calculations warrant finding stresses and strains at the cell level, a large number of elements are required to perform the discrete cell level calculations. It is therefore desirable to develop a continuum level characterization of the honeycomb (e.g., Refs. 1 2).

With regard to the development of a continuum model, one issue that has been overlooked is the scaling of honeycomb properties with respect to cell size. That is, one requires identifying certain geometrically based repeating units of the honeycomb (representative unit cell-RUC) and establishing the independence (or lack thereof) of honeycomb properties with respect to the number of such RUC's. By definition, RUC properties should be scalable for a large number of cells. However, such scaling with respect to honeycomb out of plane properties has not been examined experimentally.

This issue was addressed briefly in Ref. 3, but was done for large groups of cells.

The present study is a preliminary report on ongoing work that is focussed on examining size effects in the out of plane compressive crushing of circular cell polycarbonate (PC) honeycomb. The results obtained from an experimental program that applied quasi-static loads in the out of plane direction to honeycomb specimens clamped at both the top and the bottom edges will be presented and discussed. The out of plane response of the honeycomb as a function of specimen size will be discussed.

In addition, research to date of a finite element model aimed at predicting the specimen behavior will be presented.

\section{Crush Testing}

\section{$\underline{\text { Test Specimens }}$}

Test Specimens were made of polycarbonate circular cell honeycomb purchased form Plascore, in Zeeland, MI. This is the same material studied in Ref. 1 and Ref. 2. The individual cells have a radius of 0.0625 inches and a wall thickness of $5.068 \times 10^{-3}$ inches. The specimens had an out of plane height of 1.0 inch. The polycarbonate had the following material properties: Young's Modulus $\mathrm{E}=351.5 \mathrm{Ksi}$, and Poisson's ratio $\mathrm{v}=0.3$.

Test specimens were carefully prepared individually by hand so that the external

\footnotetext{
* Undergraduate Research Assistant and Professor of Aerospace Engineering, respectively. Copyright @2002 by Anthony M. Waas. Published by the AIAA, with permission.
} 
specimen walls were free from broken cells and remnants of the cells they were cut away from. Specimens were cut into twenty-four different sizes. The size of the samples was quantified by the number of cells $(\mathrm{N})$ that the sample contained. All sizes between one cell and nineteen cells $(\mathrm{N}=1-19)$ were studied along with specimens where $\mathrm{N}=37,61,91,127$, and 169. Pieces of flat aluminum were glued to the top and bottom of each specimen surface (these surfaces were machined flat and parallel) with epoxy in order to clamp it during testing. The specimens were placed under light pressure in the same loading jig that would be used for the crush tests, while the thin layer of epoxy cured. This was done to improve bonding performance and ensure that the edges would be completely clamped during testing.

Some specimens were tested without any epoxy and the results showed that clamping (via the epoxy) had no effect on the crushing strength of the specimens.

\section{Testing Method}

A screw driven testing machine was used to perform the crush experiments. Uniaxial out of plane compressive quasi-static crushing loads were measured under displacement control conditions with the use of a load cell. The rigid load frame crush platen movement and a LVDT were used to calculate the macroscopic strain ${ }^{\dagger}$ based on the total specimen contraction at any point in time during crushing. Specimens were placed on a level surface that was parallel to the load frame crush platen. The crush platen was moved downward with constant velocity. Out of plane crushing load and total specimen strain were measured at a sampling rate of $2 \mathrm{~Hz}$. Each sample was loaded until the specimen was fully crushed to a total height between $5 / 16^{\text {ths }}$ and $3 / 8^{\text {ths }}$ of an inch. At this point, a visible increase in load was recorded, indicating material consolidation. Fig. 1 shows pictures of undeformed and deformed (fully crushed) samples for a seven cell $(\mathrm{N}=7)$ specimen.

\footnotetext{
* Macroscopic strain is defined as crush displacement divided by the original length of the specimen. The resulting

Macroscopic stress-strain curve is similar to the P- $\Delta$ curve in a stability problem
}

\section{Material Behavior}

The behavior of all the specimens was characterized by an initial period of stiff linear response followed by the achievement of a maximum stress $\left(\Sigma_{\max }\right)$. During this period, the load rose very quickly until a macroscopic strain of about 0.02 was reached. At this point the load reached its maximum value. When this occurred, there was no noticeable deformation in the specimen. Immediately after the maximum load was reached, a well-defined localized buckle formed around the circumference of the specimen. The buckle pattern was located a short distance (approximately 0.2 inches in the crush direction from the top edge of the specimen). At this point, the load was seen to drop very quickly. After this, the single buckle zone began expanding along the crush axis of the specimen and a sizable region of crush (a crush zone) at a constant state of stress (plateau stress $\left.\left(\Sigma_{\text {plateau }}\right)\right)$ was observed. Eventually, the crush zone covered the entire length of the specimen. This is when material consolidation occurred, and the load was seen to increase again. A typical response diagram in macroscopic stressmacroscopic strain space is as indicated in Fig. 2, $\left(\Sigma_{\max }\right.$ and $\Sigma_{\text {plateau }}$ are shown in Fig. 2), for a honeycomb sample $(\mathrm{N}=7)$.

\section{Experimental Results}

A total of approximately 109 specimens were tested. The results were analyzed by converting the load measured during testing to axial stress and examining the macroscopic stress-strain response. To do this, we had to calculate the enclosed area of each specimen and divide the load by that area to get macroscopic stress. This process was not trivial. As shown in Fig. 3 for a specimen sample with $\mathrm{N}=7$, there are small, triangle-shaped holes that are present between the circular cells of the honeycomb. These holes, though small, mu st still be accounted for when finding the enclosed area of the specimens. To find the area of these holes we observed that the triangle drawn in Fig. 3 has the same area as one-half of a circular cell plus one small hole. By subtracting one-half the area of a circular cell from the area of the triangle, we found the area of the small holes to be $6.299 \times 10^{-}$ 4 in $^{2}$. 
We focused our study on two major properties of every test, $\Sigma_{\max }$ and $\Sigma_{\text {plateau }}$. Table 1 contains data that includes average values of $\Sigma_{\max }$ and $\Sigma_{\text {plateau }}$ for each size specimen with standard deviation. By plotting $\Sigma_{\max }$ and $\Sigma_{\text {plateau }}$ against number of cells $\mathrm{N}$ (Fig.4) we saw that specimens with $\mathrm{N}<19$ had a higher $\Sigma_{\max }$, and more specifically that there was a peak at $\mathrm{N}=7$. We also added error bars with a range of plus/minus one standard deviation (Fig. 5). Observing the results in Figure 5, we notice that the $\Sigma_{\text {plateau }}$ was much more consistent than $\Sigma_{\text {max }}$. This can be attributed to the fact that $\Sigma_{\max }$ is affected by a number of factors, the most important of which are any initial geometric imperfections and any irregularities with the method of load application. Thus, it is expected that it would be difficult to reproduce $\Sigma_{\max }$ with extreme precision. Achieving $\Sigma_{\text {plateau }}$ is much less prone to any initial geometric imperfections and therefore easier to reproduce with good precision.

\section{Finite Element Analysis}

In order to check the accuracy of the laboratory tests, a finite element model of the homeycomb was developed using the commercial software packages SDRC-IDEAS and Abaqus. S8R thin shell, eight noded elements were used. First a cross section was created in IDEAS out of circles (though we know that the actual specimens do not contain exactly circular cells, with point contact between neighboring cells). This cross section was next extruded to create the mesh corresponding to the honeycomb cells.

The finite element models created in IDEAS were exported to a file that could be used by Abaqus. The finite element (FE) analysis carried out in Abaqus incorporated nonlinear geometry and was carried out using the Riks method option, so that all equilibrium solutions (stable and unstable ones) could be captured. Boundary displacement loading in the shell generator direction as was done in the experiment was used.

In stability problems of this type, it is well known that the axial response is affected by initial geometric imperfections and the degree of non-linearity exhibited in the material response curve. Polycarbonate can be modeled to a reasonable level of accuracy as a solid obeying $\mathrm{J} 2$ incremental theory of plasticity. The uniaxial stress-strain curve of polycarbonate has been reported in Ref. 1, however, in the present work, single polycarbonate circular cells were cutout from the larger honeycomb sheets and using special end fixtures these single cells were loaded in tension, from which the stress-strain behavior was extracted. The stress strain curves from several such tests as well as that reported earlier in Ref. 1, are all shown in Figure 6 . The shaded area in the figure shows the bounds of the linear response. In the single cell tension tests, the material fractured prior to exhibiting the larger "plastic" range.

In order to study the combined affects of material properties and geometric imperfections, the material response of polycarbonate was assumed to be modeled through $\mathrm{J} 2$ incremental theory of plasticity with a piecewise linear uniaxial stress-strain curve. The initial slope of the curve (the elastic part) and the slope of the plastic part were retained as variables. All of the FE analyses reported here were conducted on specimens with seven cells. The intention is to follow this initial analysis with similar analyses for the other specimens with varying cell sizes. The procedure for the FE analyses was as follows; First, an eigenmode analysis was carried out to determine the lowest three axial buckling modes. The mode corresponding to the smallest eigen value was used as an initial imperfection shape and the "perfect" shell mesh was perturbed by a pre-determined magnitude of this lowest eigenmode shape. This was followed by the response analysis incorporating the Riks method option.

Figure 7 shows a comparison of the P- $\Delta$ response curves (axial load against shell edge axial displacement) as predicted by the FE runs using only linear elastic properties, against the experimental results. An imperfection magnitude of $0.2 \%$ of the wall thickness was used. The experimental results showed maximum loads of approximately 90, 88 and $73 \mathrm{lbs}$. respectively. The FE prediction was $94 \mathrm{lbs}$, and this corresponded to the formation of the circumferential localized buckle pattern, very much like observed in the experiment. The FE simulation used a Young's modulus of 273,000 Psi and a poisson's ratio of 0.3 . Figure 8 shows results corresponding to an elastic-plastic shell analysis compared against experiment. In the piecewise linear representation, the elastic part had a slope of 273,000 Psi, and the plastic part 


\begin{abstract}
was assumed to have a slope of 58,000 Psi, which is equal to the tangent modulus of the original stress-strain curve (ref. 1) at a strain of 0.0275 . The FE results predict a maximum load of approximately 75 lbs., which is in the range of the experimentally measured values. Beyond this load, the deformation localized and a plateau load of approximately $65 \mathrm{lbs}$. was obtained. This load plateau is higher than the experiment, which was consistently about 20-30 lbs. Further analyses will be conducted to examine the combined effect of material properties and imperfections on the maximum load and plateau load, as a function of cell size. This will be done with a view to determining the effect of $\mathrm{N}$ on the maximum load and the plateau load. Other geometric imperfections, such as finite length contact regions between the cells (contrasted against point contact as is assumed in the present FE analyses) will also be examined in the furture.
\end{abstract}

\section{Concluding Remarks}

The effect of cell size on the out of plane compressive crushing response of circular cell polycarbonate honeycomb has been studied experimentally and numerically. The results show that a significant increase in compresive strength is observed for specimens having cells sizes in the range $\mathrm{N}=1-18$. The maximum crushing load was observed where $\mathrm{N}=7$. Finite element (FE) analysis was used to simulate the behavior of the specimens during crushing.
Preliminary FE results are in good agreement with experiment and show that a well defined circumferential buckle (localized) is responsible for initiating the mechanism of collapse. The present FE model, which was developed for 7 cells $(\mathrm{N}=7)$, will be expanded for different values of $\mathrm{N}(\mathrm{N}=1-169)$ with a view to establishing the reasons for size effects, in future work.

\section{Acknowledgements}

The authors are grateful to John Donovan, V, Aerospace Undergraduate Senior, who helped with the experimental work reported herein.

\section{$\underline{\text { References }}$}

1. J. Chung and A. M. Waas, "In-plane biaxial crush response of polycarbonate honeycombs", J. Engrg. Mech., ASCE, Vol. 127, No. 2, pp. 180, 2001.

2. J. Chung and A. M. Waas, "Compressive response and failure of circular cell polycarbonate honeycombs under inplane uniaxial stresses", J. Eng. Mat. Tech., Vol. 121, No. 4, pp. 494, 1999.

3. H. Zhao and G. Gary, "Crushing Behavior of Aluminum Honeycombs Under Impact Loading," Int. J. Impact Engng, Vol. 21, 1998, pp. 827-836.

4. Enoba Wu and W-S. Jiang, "Axial Crush of Metallic Honeycombs," Int. J. Impact Engng, Vol. 19, 1997, pp. 439-456. 

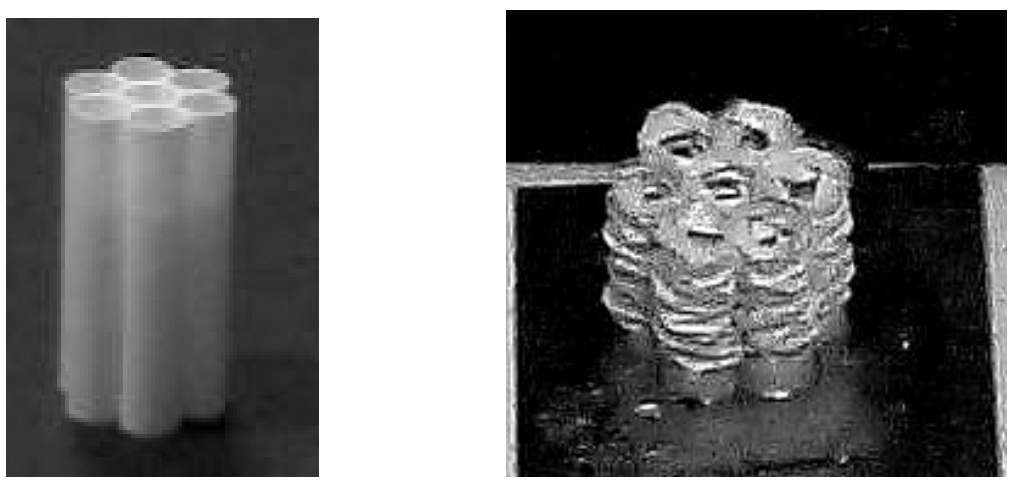

Fig. 1 Pictures of an undeformed and a fully crushed specimen for $\mathrm{N}=7$.

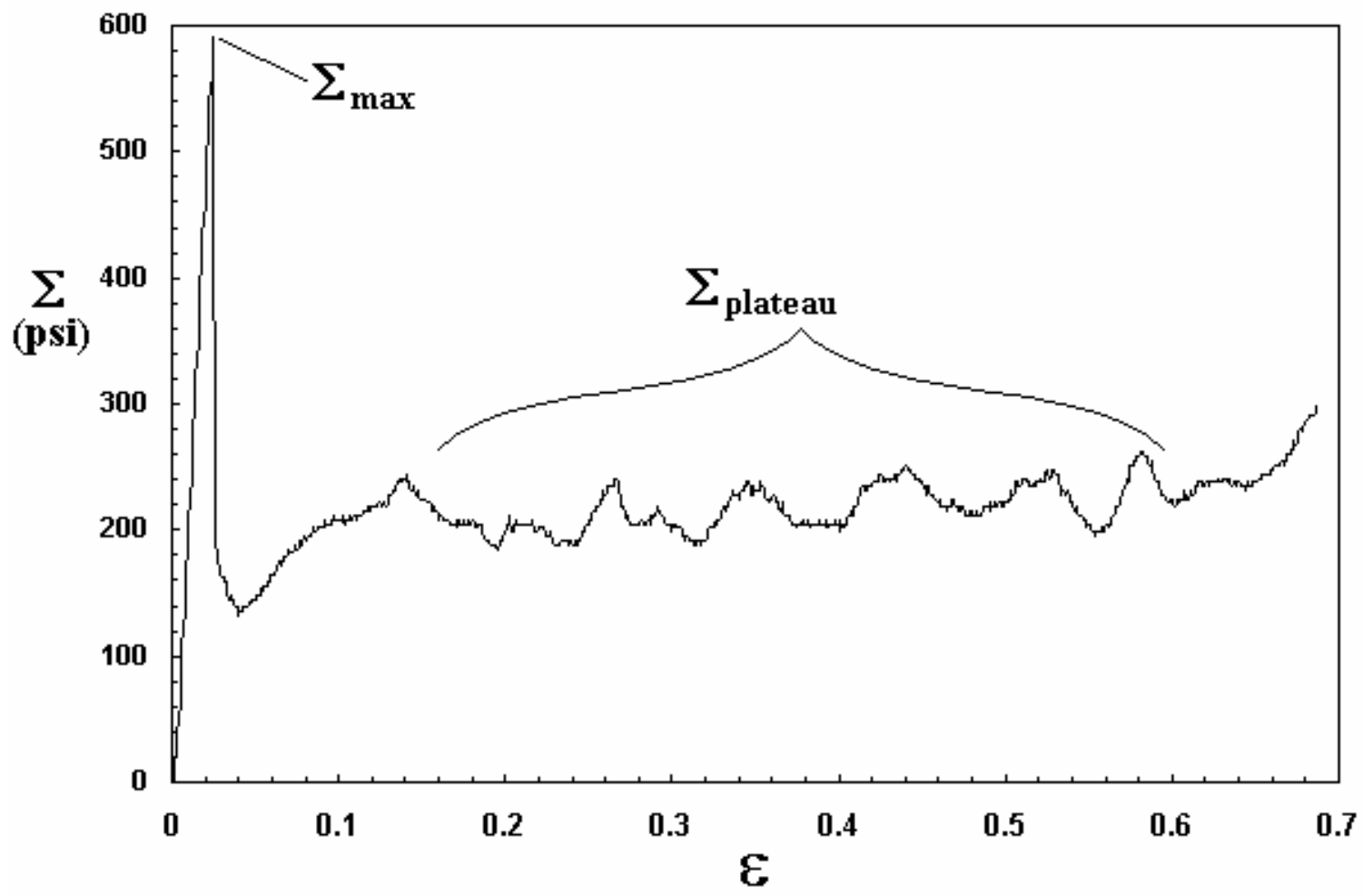

Fig. 2 A typical $\Sigma$ verses $\varepsilon$ graph for $N=7$. 
AIAA 2002-1766

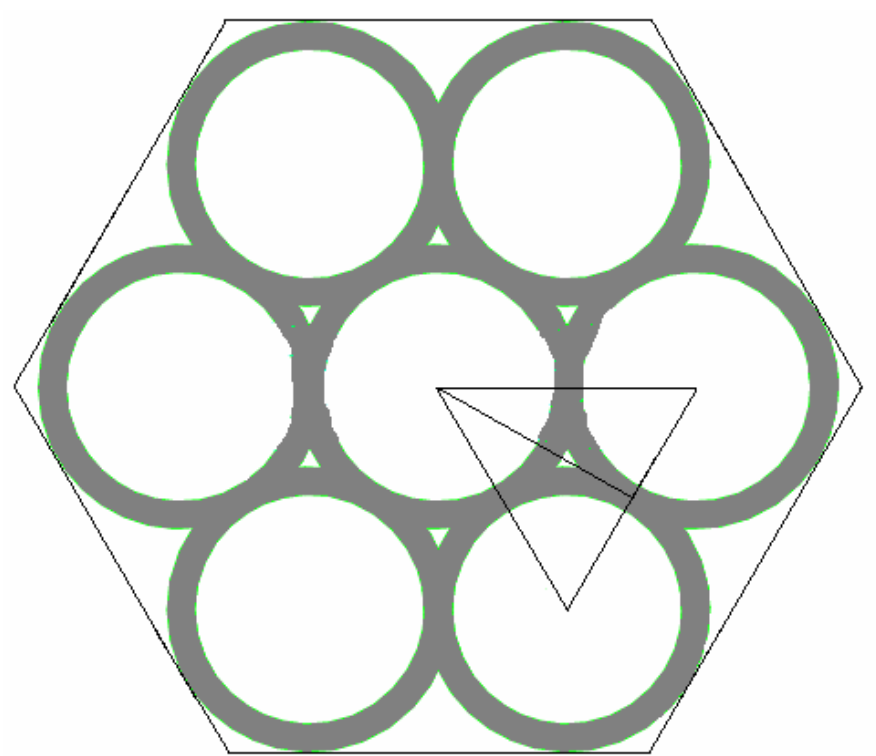

Fig. 3 A diagram of the cross-section of a specimen where $N=7$. Using the triangle drawn on the diagram, we determined that the small triangle-shaped holes had an area of $0.00103 \mathrm{in}^{2}$.

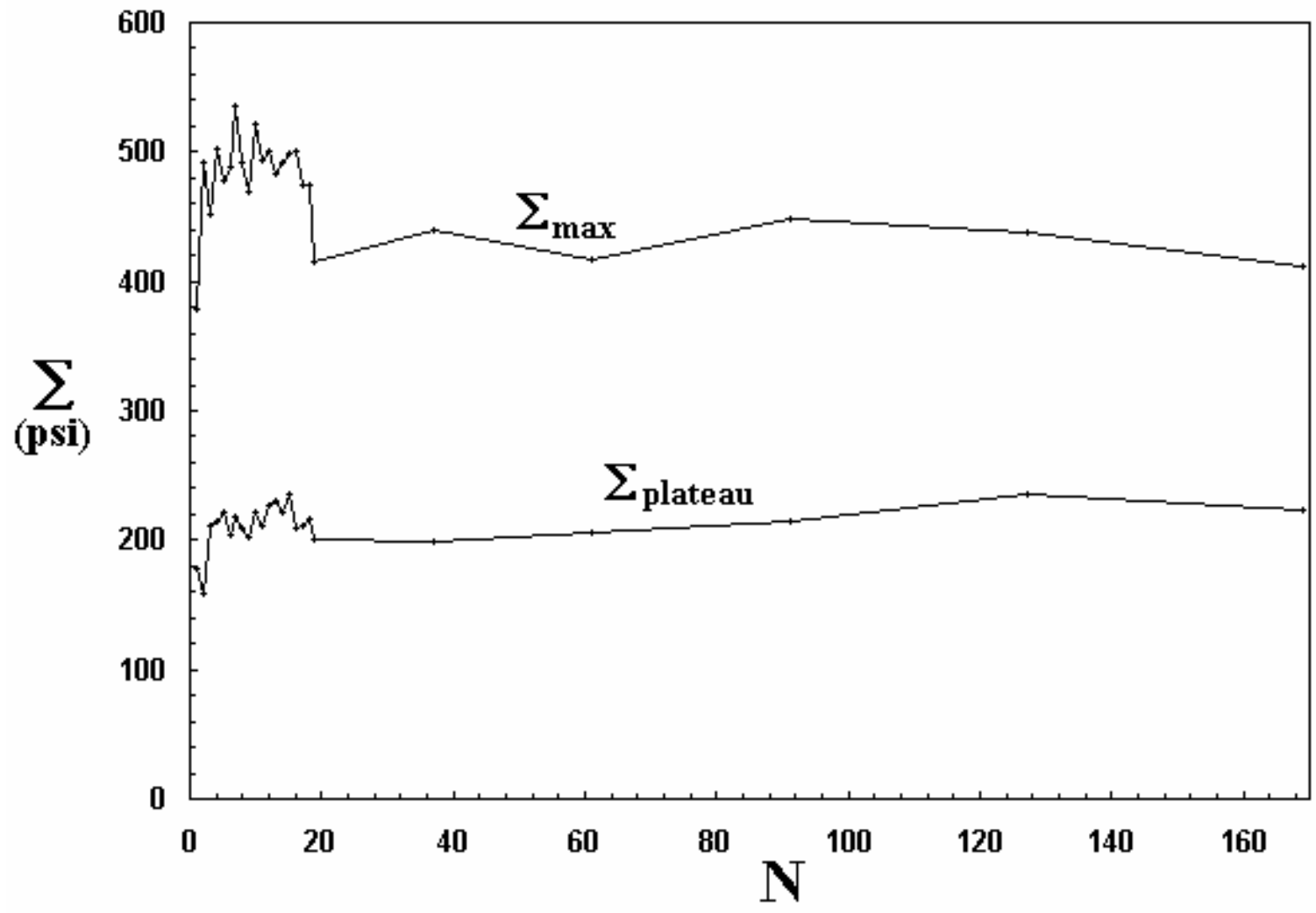

Fig. 4 Average $\Sigma_{\max }$ and $\Sigma_{\text {plateau }}$ data for all values from $N=1$ to $N=169$. 
AIAA 2002-1766

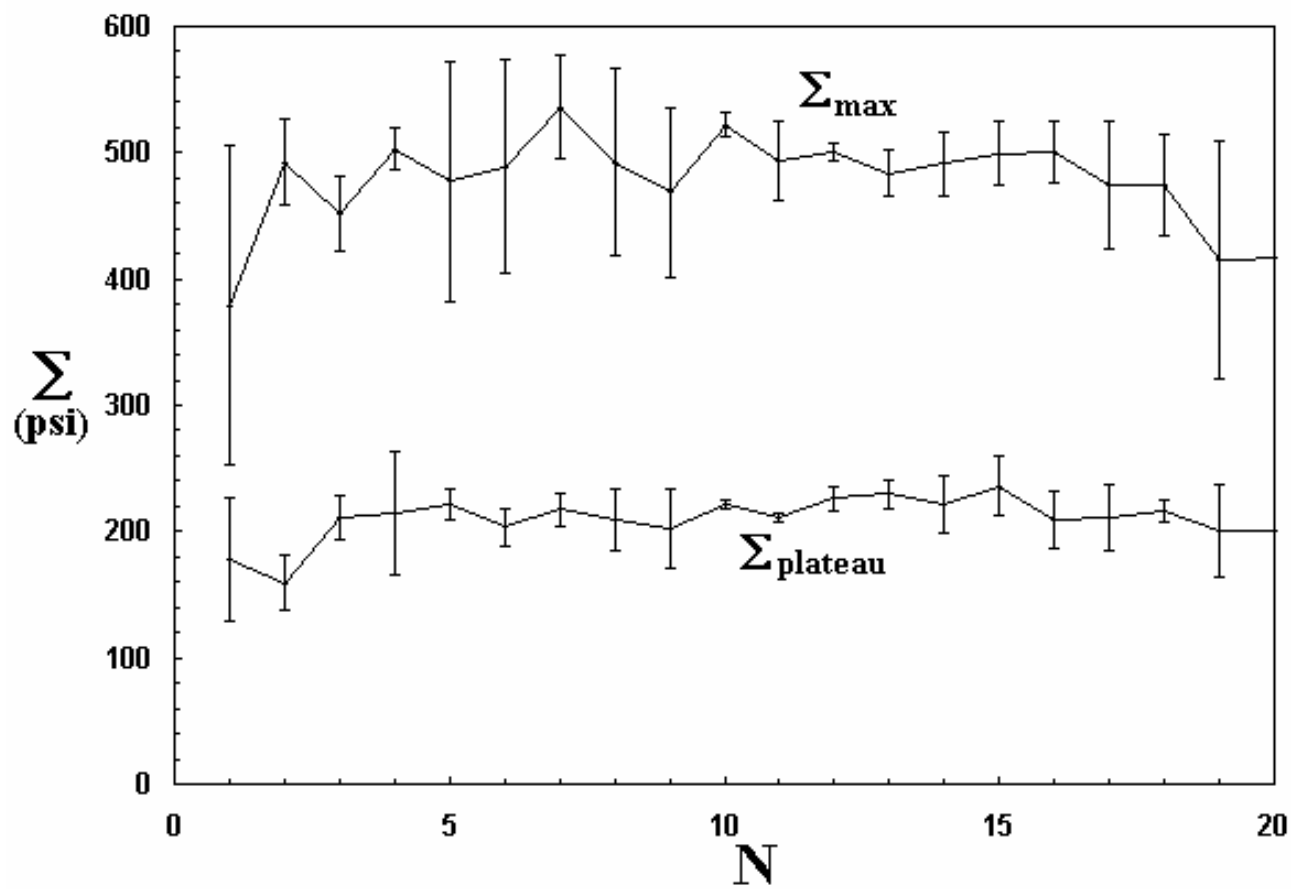

5a) Average $\Sigma_{\max }$ and $\Sigma_{\text {plateau }}$ for specimen sizes from $\mathrm{N}=1$ to $\mathrm{N}=19$ with error bars.

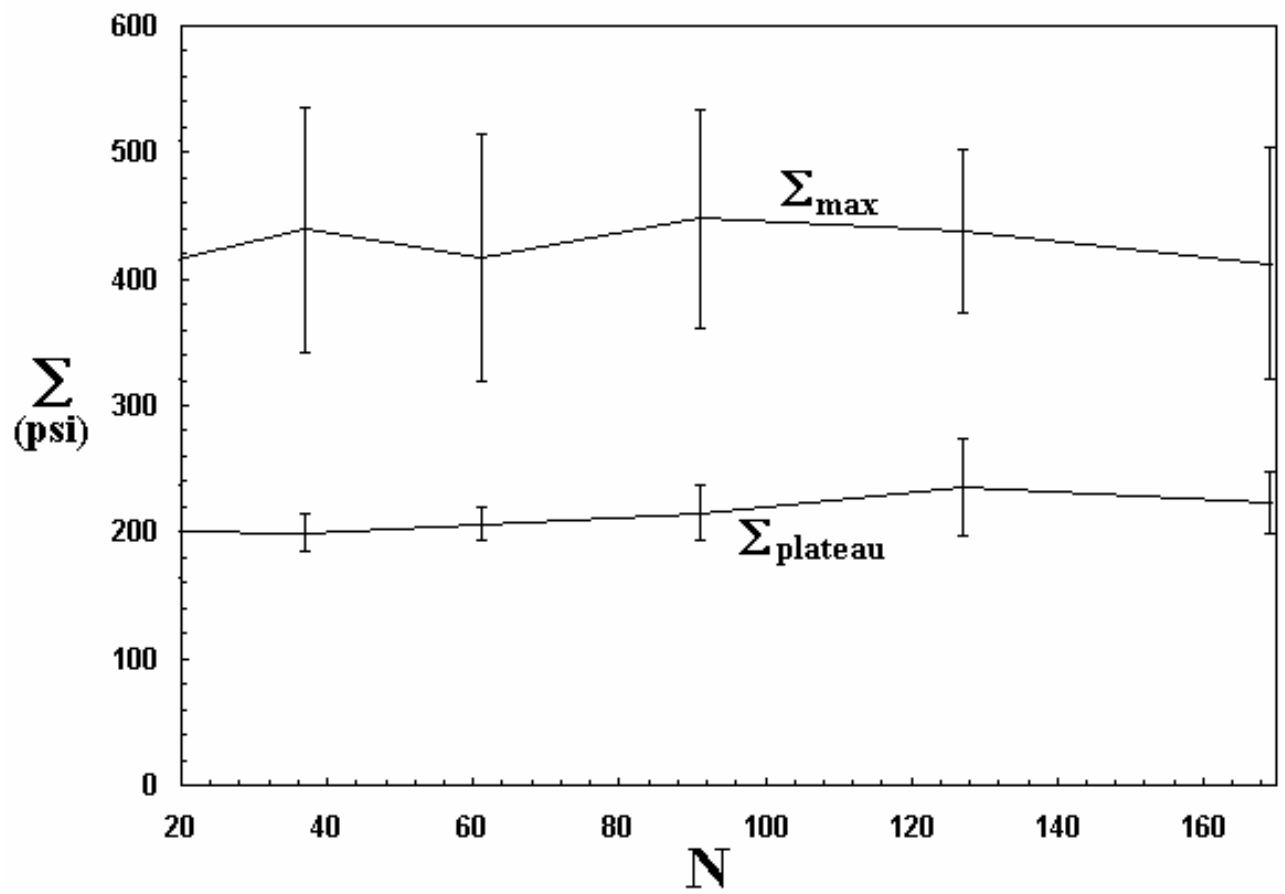

5b) Average $\Sigma_{\max }$ and $\Sigma_{\text {plateau }}$ for specimen sizes from $\mathrm{N}=20$ to $\mathrm{N}=169$ with error bars.

Fig. 5 Size dependence of $\Sigma_{\max }$ and $\Sigma_{\text {plateau }}$ showing one standard deviation error. 
Table $1 \Sigma_{\max }$ and $\Sigma_{\text {plateau }}$ data with averages and standard deviations.

\begin{tabular}{|c|c|c|c|c|}
\hline $\begin{array}{l}\text { Number of } \\
\text { Cells }\end{array}$ & $\begin{array}{c}\Sigma_{\max } \\
\text { Average } \\
\text { (psi) }\end{array}$ & $\begin{array}{c}\sum_{\max } \\
\text { St Dev } \\
\text { (psi) }\end{array}$ & $\begin{array}{c}\Sigma_{\text {plateau }} \\
\text { Average } \\
\text { (psi) }\end{array}$ & $\begin{array}{c}\Sigma_{\text {plateau }} \\
\text { St Dev } \\
\text { (psi) }\end{array}$ \\
\hline 1 & 379.1 & 126.3 & 177.9 & 48.2 \\
\hline 2 & 492.3 & 34.3 & 159.4 & 22.0 \\
\hline 3 & 451.0 & 29.7 & 211.3 & 17.7 \\
\hline 4 & 502.8 & 16.3 & 214.5 & 49.2 \\
\hline 5 & 477.4 & 95.1 & 221.3 & 12.1 \\
\hline 6 & 489.0 & 84.6 & 203.4 & 14.5 \\
\hline 7 & 536 & 40.4 & 217.2 & 13.2 \\
\hline 8 & 492 & 74.6 & 209.4 & 24.8 \\
\hline 9 & 468 & 66.6 & 202.8 & 31.2 \\
\hline 10 & 522 & 9.3 & 221.8 & 3.9 \\
\hline 11 & 493 & 31.4 & 210.6 & 3.8 \\
\hline 12 & 500 & 7.3 & 226.3 & 10.0 \\
\hline 13 & 484 & 18.7 & 229.5 & 11.1 \\
\hline 14 & 491 & 24.8 & 221.9 & 23.0 \\
\hline 15 & 499 & 25.2 & 236.1 & 23.1 \\
\hline 16 & 501 & 27.6 & 209.2 & 23.2 \\
\hline 17 & 474 & 50.7 & 211.3 & 26.5 \\
\hline 18 & 474 & 40.0 & 215.6 & 8.9 \\
\hline 19 & 415 & 93.8 & 200.5 & 36.2 \\
\hline 37 & 439 & 96.5 & 199.6 & 14.5 \\
\hline 61 & 416 & 97.7 & 206.7 & 12.4 \\
\hline 91 & 448 & 86.4 & 215.0 & 22.0 \\
\hline 127 & 437 & 64.8 & 235.7 & 38.7 \\
\hline 169 & 412 & 91.6 & 223.6 & 23.9 \\
\hline
\end{tabular}


AIAA 2002-1766

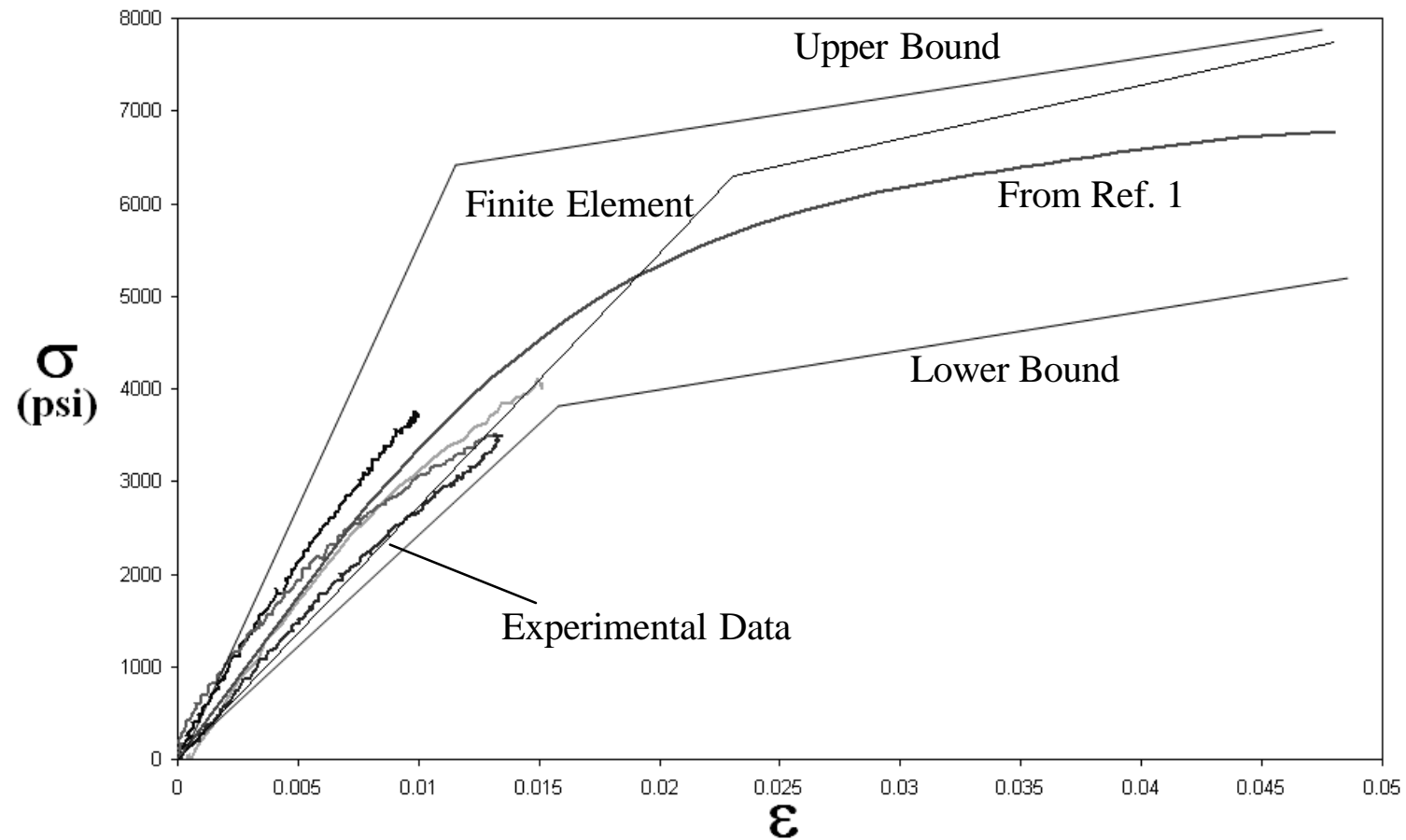

Fig. 6 Stress-strain curves for polycarbonate: experimentally measured, from Ref. 1 and bounds used for $\mathrm{FE}$ analysis.

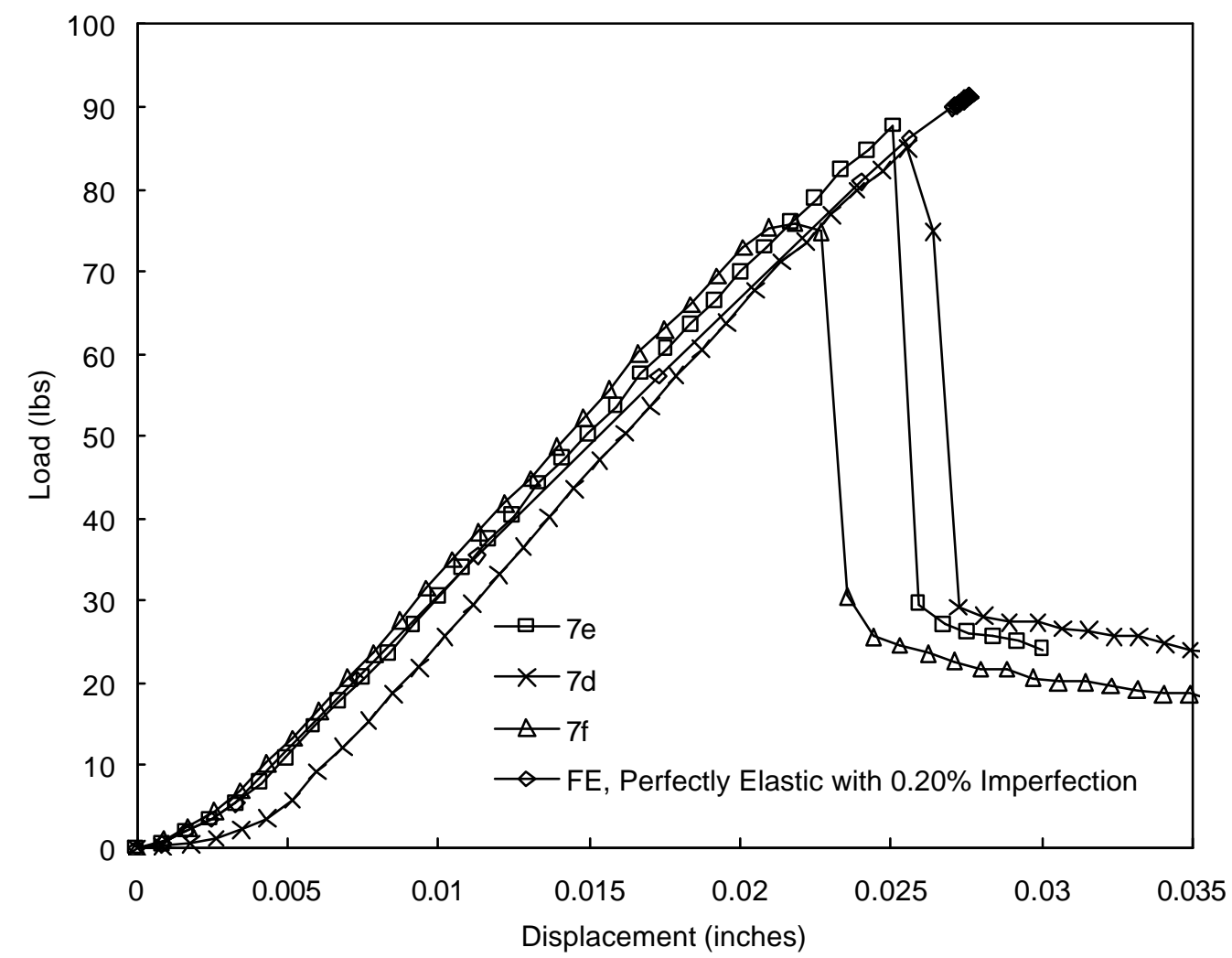

Fig. 7 Finite element response curve for the elastic case (with a $0.2 \%$ initial geometric imperfection) compared against three experimental curves for $\mathrm{N}=7$ cells. 
AIAA 2002-1766

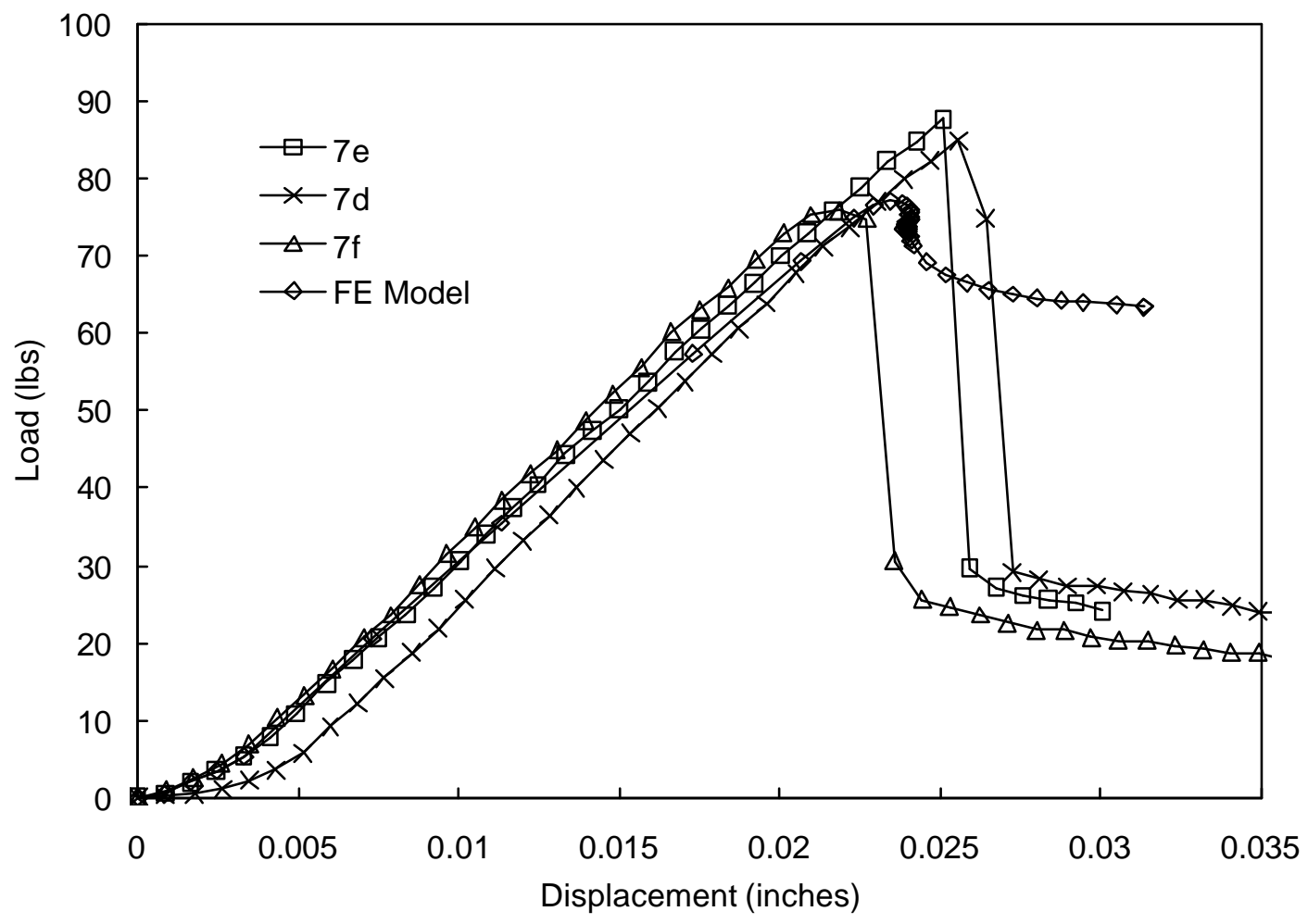

Fig. 8 Finite element response curve for the elastic-hardening plastic case $(0.2 \%$ initial geometric imperfection) compared against three experimental curves for $\mathrm{N}=7$ cells. 